\title{
Desenvolvimento de games na Língua Inglesa: lógica e criatividade na construção do conhecimento
}

\author{
Vinicius Carvalho de Aragão Santana ${ }^{1}$, Rachel de Sousa Ferreira ${ }^{1}$ \\ ${ }^{1}$ Colégio Andrews - Rio de Janeiro - RJ - Brasil \\ vinyaragao@hotmail.com, rachelferreirabr@gmail.com, \\ \{vinicius, rachelferreira\}@andrews.g12.br
}

\begin{abstract}
The article discusses a game development experience by fifth year elementary private school students. The activity integrated with the English subject shows that the creation of digital games can strengthen the development of knowledge in a playful and creative way, and at the same time exercise programming logic and the foreign language.

Resumo. O artigo aborda uma experiência de desenvolvimento de games vivenciada por alunos do quinto ano do ensino fundamental de uma escola privada. A atividade integrada com a disciplina de Inglês, mostra que a criação de jogos digitais pode consolidar a construção de conhecimento de forma lúdica e criativa, e ao mesmo tempo trabalhar a lógica de programação e a língua estrangeira.
\end{abstract}

\section{Introdução}

Cada vez mais a tecnologia utilizada na educação vem ganhando espaço no cenário atual. Além de propiciar novas possibilidades no processo de ensino e aprendizagem, estimula a criatividade, o trabalho colaborativo, o pensamento lógico e oferece diferentes métodos de construção do conhecimento. Segundo Silva (2016):

\footnotetext{
"Com as novas tecnologias surgem diversos questionamentos e inquietações, várias formas de se comunicar, de ensinar, de aprender; há um novo olhar para ler a realidade e escrever sobre e para o mundo. É preciso saber como essa nova forma de organizar as informações pode incutir novos hábitos de pensamento nos sujeitos - pela confluência de várias mídias, pela conjunção de signos, e, consequentemente, pela (re)construção de significados assim como a criação de interfaces mais amigáveis, que valorizam o aspecto visual, representadas por ícones." (Silva,2016, p.2)
}

O mundo conectado exige que o indivíduo possua conhecimentos tecnológicos para alcançar seus objetivos. A escola, ao estimular o uso de mídias digitais, contribui para que o aluno se desenvolva de forma completa.

Diante disto, o objetivo deste artigo é relatar a experiência vivenciada pelos alunos do $5^{\circ}$ ano do ensino fundamental de uma escola privada durante as aulas de inglês, ao realizarem um projeto interdisciplinar de desenvolvimento de games. Sua finalidade era ampliar o vocabulário construído, além do uso correto dos verbos em inglês, utilizando como tema a Sustentabilidade do Planeta.

Discutiremos, também, a importância de projetos que envolvem tecnologia como alicerce para promover o ensino, assim como suas implicações pedagógicas. Este trabalho foi inspirado em outros que também utilizaram a criação de jogos digitais para incentivar a aprendizagem como o artigo de Shimohara, Sobreira e Ito (2016), que teve como 
propósito auxiliar os alunos da escola básica a criarem jogos que fossem desafiadores e atrativos e que ao mesmo tempo envolvessem os conteúdos curriculares.

Temos como objetivo contribuir para que novos projetos surjam abrindo os horizontes dos alunos, capacitando-os para selecionar, organizar e buscar informações com autonomia no seu processo de construção do conhecimento nos diversos campos do saber.

\section{Métodos}

Durante as aulas de inglês do $5^{\circ}$ ano o tema que estava em pauta era a sustentabilidade. Os alunos apresentaram grande interesse no que diz respeito a importância da água, e os cuidados que todos devem ter para não desperdiçá-la.

Entretanto, um outro assunto surgia em paralelo nas conversas dos alunos, os jogos digitais. Através de uma votação, eles optaram pela programação de games, como meio de desenvolver as atividades da disciplina.

Foi acordado com a turma que o game que iriam programar deveria ter caráter informativo, onde as informações pesquisadas surgissem no decorrer do jogo, escrito na língua inglesa, utilizando os verbos e o vocabulário construído durante as aulas.

Foram apresentados ao site Code.org, onde puderam ver diferentes tipos de jogos e realizar experiências de programação através de games como Minecraft e Star Wars. Esta atividade fez com que obtivessem parâmetros para futuramente criarem seus próprios jogos.

Posteriormente realizaram pesquisas sobre o tema e levantaram ideias para produzir o plano do game. O desenvolvimento do roteiro teve como objetivo trabalhar a construção de textos em Inglês, dando sentido e coerência às frases e ampliando o vocabulário. Para trabalhar a oralidade, os grupos apresentaram seus roteiros para a professora e os demais colegas através de cartazes e desenhos.

O software escolhido para realizar o desenvolvimento do game foi o Constructor. Embora não seja simples, ele apresenta uma linguagem adequada para que as próprias crianças façam a programação. Ele desafia os alunos e instiga a sua criatividade, pois permite que os componentes do jogo, como cenário e personagens, possam ser importados da internet, desenhados ou um misto de ambos. Outro fato interessante é a possibilidade do aluno testar o funcionamento do que programou concomitantemente ao desenvolvimento da programação, fazendo com que o estudante possa analisar os erros rapidamente e procurar novas soluções.

Por ser uma plataforma que produz jogos muito semelhantes aos que os alunos costumam jogar nos seus momentos de lazer, eles conseguem visualizar uma conexão entre o projeto que está sendo construído e o produto final. Este fato é um estímulo para que desejem vê-lo concluído.

A decisão de dividir a turma em nove duplas foi proposital. $\mathrm{O}$ trabalho em equipe foi um dos pontos centrais, uma vez que, ao debater ideias e discutir soluções, ambos crescem. Além disso, quando programa-se em dupla é possível ver diferentes caminhos para chegar ao mesmo objetivo, o que favorece a discussão sobre a solução mais adequada para resolver o desafio que se apresenta. Segundo Piaget apud Silva, Menezes e Fagundes (2016):

“Outro fator importante é o trabalho, que é realizado em equipe, o aluno não é um ser passivo, mas sim ativo, a sua forma de pensar contribui para que ele tenha somente o seu ponto de vista, porém quando se une aos seus colegas poderá ter a 
VI Congresso Brasileiro de Informática na Educação (CBIE 2017)

Anais dos Workshops do VI Congresso Brasileiro de Informática na Educação (WCBIE 2017)

possibilidade de enxergar outras formas de pensar e também outros pontos de vista, sendo a cooperação um instrumento necessário para a formação do pensamento racional”. (SILVA, MENEZES E FAGUNDES, 2016, p. 817)

Ao colocar em prática todo o planejamento que foi elaborado anteriormente, os alunos começaram a desenvolver suas primeiras linhas de código, transformando textos e desenhos em lógica de programação. Cada função como: pular, correr ou andar, teve que ser devidamente delineada para que cada ação realizada pelo personagem tivesse uma reação correspondente. Segundo Wing apud Ribas, Dal Bianco e Lahm (2016):

“As Ciências da Computação trabalham com muitos princípios de matemática e engenharia. Logo, ao ter contato com a programação, por exemplo, o usuário tende a interagir diretamente com essas áreas, fator que reforçará ou estimulará seu conhecimento lógicomatemático (...) É possível trabalhar com técnicas de programação ou elementos que a integram sem conhecimento específico ou avançado sobre o assunto. " (RIBAS, DAL BIANCO E LAHM, 2016, p.4)

Em alguns casos o que desejavam realizar era tão complexo, que ocasionou frustrações momentâneas. Entretanto ao procurar soluções na rede, sob a mediação do professor de informática e através da contribuição do coletivo, os jogos aos poucos foram ganhando corpo e consistência.

Nas últimas aulas, as duplas já estavam com seu game praticamente pronto. Então iniciou-se a fase em que cada grupo experimentou os jogos uns dos outros em busca de bugs (erros), dando sugestões e oferecendo um olhar externo para o trabalho dos colegas.

No momento, os jogos estão na fase de testes e finalização, para que no final do semestre os pais e a comunidade escolar possam jogá-los.

\section{Resultados, discussão e conclusão}

Ao programarem os jogos, os alunos foram atingidos por uma onda motivacional que os impulsionou em diversos aspectos pedagógicos importantes. $\mathrm{O}$ envolvimento com $\mathrm{o}$ projeto fez com que os momentos de construção do trabalho, que ocorriam primeiramente uma vez por semana, fossem ampliados. Nos intervalos, eles passaram a frequentar o laboratório de mídias para programar, sem qualquer imposição dos professores. Outros estudantes que não faziam parte do grupo, ao observá-los criando seus games demonstraram interesse em participar. Muitos deles eram de séries mais avançadas e ajudavam os outros mais jovens.

Os alunos usaram a imaginação para dar vida ao jogo, portanto, cada proposta teve diferentes: cenários, personagens, fases e desafios. O interesse fez com que pesquisassem em casa e nas aulas, através de vídeos, grupos de discussão na internet e pedindo ajuda uns aos outros. Estes impulsos aconteceram de maneira espontânea e pôdese avaliar que a proposta principal foi atingida, ao passo em que buscavam o conhecimento com autonomia.

A criatividade e a ludicidade foram incentivadas a todo o momento, desde a fase de roteirização até a criação. Eles tiveram liberdade de usar a imaginação para construir seus mundos virtuais, pesquisando na internet os personagens e os elementos do game. Personalizando-os como queriam.

A união das tecnologias digitais com o estudo da língua inglesa favoreceu o entendimento e a potencialização do uso das línguas estrangeiras. De acordo com os 
VI Congresso Brasileiro de Informática na Educação (CBIE 2017)

Anais dos Workshops do VI Congresso Brasileiro de Informática na Educação (WCBIE 2017)

relatos da professora, a turma apresentou melhoras significativas nas notas e passaram a perguntar mais sobre o vocabulário, construção de frases e tempo verbal para utilizar nos seus jogos.

A discussão sobre o meio ambiente alavancou e os debates tornaram-se mais profundos. Durante a fase de pesquisa, muitas questões foram levantadas, principalmente em relação ao desperdício de água que foi o assunto que mais despertou interesse dos alunos. Eles puderam ver em sites de notícias e revistas virtuais, a importância do ecossistema e como o homem vem degradando a natureza. O debate foi além, e eles puderam sugerir soluções para as questões levantadas, isto é, maneiras de contribuir para o cuidado com a natureza. O resultado de toda esta pesquisa foi passado para o game, fazendo com que as missões tivessem o objetivo de ensinar e informar o jogador.

Não existem regras para desenvolver projetos que incentivem a autonomia e a criatividade, mas ao buscar diferentes maneiras de propiciar a aprendizagem, a sala de aula se renova a todo momento. Essa construção torna a escola um ambiente colaborativo, que permite que o aluno busque novos caminhos para aprender.

\section{Referências}

Shimohara, C., Sobreira, E., Ito,O. Potencializando a programação de jogos digitais de matemática através do Scratch e da avaliação Game Flow. Anais do XXII Workshop de Informática na Escola (WIE 2016). Disponível em: <http://brie.org/pub/index.php/wie/article/view/6850/4728> Acesso em 05 de maio de 2017

Silva, P., Menezes, C.S., Fagundes L. (2016) Aprendizagem colaborativa: desenvolvimento de Projetos de Aprendizagem em ambientes digitais. Anais do XXII Workshop de Informática na Escola (WIE 2016). Disponível em: <http://www.brie.org/pub/index.php/wie/article/view/6625/4536> Acesso em 05 de junho de 2017.

Silva, S.L. (2016). Reflexões sobre desafio das novas tecnologias na escola básica. Revista InterteXto/ ISSN: 1981-0601, v.9,n.1 (2016)

Ribas, E., Dal Bianco, G., Laham, R.A. (2016) Programação visual para introdução ao ensino de programação na Educação Superior: uma análise prática. Disponível em: $<$ http://seer.ufrgs.br/index.php/renote/article/viewFile/70671/40108> Acesso em 20 de maio de 2017. 